\title{
ESTRADIOL BLOOD LEVEL AND ESR1 GENE POLYMORPHISM IN WOMEN WITH PREMENSTRUAL SYNDROME
}

10.36740/WLek202012105

\author{
Lyudmyla V. Pakharenko' , Yuri P. Vdovichenko ${ }^{2}$, Nataliia Ya. Kurtash'1, Iryna 0. Basiuha' , Inna V. Kravchuk', \\ Volodymyr D. Vorobii ${ }^{1}$, Olena M. Kusa ${ }^{1}$ \\ ${ }^{1}$ IVANO-FRANKIVSK NATIONAL MEDICAL UNIVERSITY, IVANO-FRANKIVSK, UKRAINE \\ ${ }^{2}$ SHUPYK NATIONAL MEDICAL ACADEMY OF POSTGRADUATE EDUCATION, KYIV, UKRAINE
}

\begin{abstract}
The aim: To evaluate the association between estrogen receptor (ESR1) a-Xbal polymorphism with estradiol serum blood level in the patients with premenstrual syndrome. Materials and methods: 50 women with premenstrual syndrome and 20 controls were examined. The level of estradiol was measured in the blood serum in both phases of the menstrual cycle by ELISA method. Polymerase chain reaction was used to study ESR1 gene polymorphism (A-351G variant).

Results: The estradiol concentration was similar in two phases of the menstrual cycle between healthy women and patients with premenstrual syndrome. But the more growth of estradiol in the luteal phase was determined in the persons with premenstrual syndrome. The rate of $\mathrm{GG}$ genotype was the largest in women with severe premenstrual syndrome $\left(x^{2}=3.52, p=0.06\right)$. Also, in the persons with severe premenstrual syndrome who had $G$ allele ( $G G+A G$ genotype) the estradiol concentration in the luteal phase of the menstrual cycle was on $50.00 \%(p=0.02)$ higher compared to carriers of AA genotype. There was no difference in estradiol level between healthy women with $\mathrm{GG}+\mathrm{AG}$ genotype and AA genotype.

Conclusions: AG polymorphism of ESR1 gene may be the marker of development of premenstrual syndrome.
\end{abstract}

KEY WORDS: premenstrual syndrome, estradiol, ESR1 gene, polymorphism

Wiad Lek. 2020;73(12 p. I):2581-2285

\section{INTRODUCTION}

Affecting of women by different symptoms such as psychological (emotional liability, anxiety, irritability etc.) and physical (oedema, gastrointestinal manifestations, mastalgia, headache, skin problems etc.) ones in the luteal phase of the menstrual cycle are usually connected with premenstrual syndrome (PMS). This syndrome includes medical, psychological and social problems [1]. The rate of PMS varies in different population groups ( $12 \%$ of women suffer from PMS in France, $67 \%$ - India, $19 \%$ - Switzerland, $73 \%$ - Spain, $60 \%$ - Brazil, $98 \%$ - Iran [2]) and age (30-75\% of women in reproductive age $[3,4,5], 20-81,3 \%$ of girls and adolescents $[6,7,8], 20-32 \%$ persons in premenopause [9] have PMS). Also, such dissimilar frequency of the syndrome depends on the using of different diagnostic criteria. The most used of them were developed by American College of Obstetricians and Gynecologists [10], Royal College of Obstetricians and Gynaecologists [11]. Nowadays the International Society of Premenstrual Disorders proposed to use new classification and diagnostic standards of premenstrual disorders [12]. Together with medical problem of PMS development (complaints of the patients), social factor of PMS is one of the main features of it. Impairment of quality of life that manifests by the decrease in daily productivity and social activity often accompanies such patients [13].

Hormonal disorders especially those which are connected with the female steroid hormones, estrogens and progesterone, form the main theory of the development of PMS. Neuromediators such as serotonin, dopamine, the monoamine oxidase influence on the forming of the psychological manifestations of this syndrome. Insufficiency of some vitamins (D $[14,15], \mathrm{B} 1[16])$, microelements (calcium [15], zinc [17]) may have the attribute in the genesis of this pathology. Substantially the studies of their effectiveness are based on the positive effect with an additional intake.

Genetic contribution in the description of the details of PMS development is based commonly on the results of the family anamnesis [18]. Nowadays the role of gene polymorphism is not very clear. The fact is that the presence of the numerous clinical manifestations is connected with different pathogenetic development mechanisms related to dissimilar regulatory systems.

Aim of the study is to evaluate the association between estrogen receptor (ESR1) a- Xbal polymorphism with estradiol serum blood level in the patients with premenstrual syndrome.

\section{THE AIM}

The aim was to evaluate the association between estrogen receptor (ESR1) $\alpha$-Xbal polymorphism with estradiol serum blood level in the patients with premenstrual syndrome. 


\section{MATERIALS AND METHODS}

50 women in reproductive age with PMS formed the basic group, 25 of them had mild form of the syndrome (I subgroup), 25 - severe one (II subgroup). The diagnosis of PMS was put according to the recommendations of the Order No 676 of the Ministry of Health of Ukraine [19]. Mild PMS is the presence of 3-4 symptoms in the luteal phase of the menstrual cycle in 2-10 days before menstruation, 1-2 of them are the most pronounced; severe PMS is the presence of 5-12 symptoms in the luteal phase of the menstrual cycle in 3-14 days before menstruation, 3-4 of them are most pronounced. 20 women in reproductive age without PMS were controls. Inclusion criteria: reproductive age (18-44 years), regular menstrual cycles, the presence of PMS, written consent of the patient. Exclusion criteria: pregnancy, lactation, disorders of menstrual cycle, focal lesions of breast, abnormal uterine bleeding of unknown etiology, acute inflammation of pelvic organs, tumors of uterus and ovaries of unknown etiology, endometrial hyperplasia, genital endometriosis, severe somatic pathology in the history, organic pathology of central nervous system, mental illness, hormonal tumors, diabetes mellitus, adrenal diseases, thyroid pathology, malignant tumors in the present or in anamnesis, premenstrual dysphoric disorder, women who took psychotropic medications or hormonal therapy within the last 3 months. The clinical study was carried out in Ivano-Frankivsk Clinical Maternity Hospital (Ukraine).

The level of estradiol was determined on the $5^{\text {th }}-7^{\text {th }}$ and $18^{\text {th }}-22^{\text {d }}$ days of the menstrual cycle by ELISA method. The polymorphism of the gene was studied in the Department of Medical Genetics, Shupyk National Medical Academy of Postgraduate Education (Kyiv) in the peripheral blood, which was collected into tubes with ethylenediaminetetraacetic acid in amount of $2.7 \mathrm{ml}$. Deoxyribonucleic acid was extracted using commercial set "ДНКсорб-В” (Central Research Institute of Epidemiology, Russia) according to the instruction. Then polymerase chain reaction was done by "Fermentas" reagents (Lithuania) in the thermocycler «FlexCycler» (Analytik Jena, Germany). Restriction fragment length polymorphism was performed for study A-351G variant of ESR1 gene. The amplification products of the A-351G fragments were hydrolytically digested using the restriction endonuclease Xbal. The results of the restriction fragment length polymorphism were taken into account by conducting the electrophoresis of the resulting fragments in $2 \%$ agarose gel (Fermentas agarose) with the addition of ethidium bromide and subsequent visualization using the Vitran computer system.

The statistical data were calculated in program Statistica 6.0. We used descriptive statistics (arithmetic mean value, average standard error), nonparametric statistics - Wilcoxon and Mann-Whitney tests; criterion $\chi^{2}$ (Yates corrected Chi-square), odds ratio (OR), confidence interval (CI).

\section{RESULTS}

There was no significant difference in the average age of persons in the control $(27.16 \pm 1.09$ years $)$ and the basic groups (29.42 \pm 0.84 years). Gynecological pathology was typical as for healthy women $(21(84.0 \%))$ as for patients with PMS (46 (92.0\%)). In anamnesis 42 persons with PMS (84.0\%) and 15 control women (60.0\%) suffered from the inflammatory processes of the appendages $\left(\chi^{2}=4.03, \mathrm{p}=0.045 ; \mathrm{OR}=3.50,95 \%\right.$ CI 1.16-10.52, $\left.\mathrm{p}=0.03\right)$, $23(46.0 \%)$ and $11(44.0 \%)$ women respectively - from the inflammatory diseases of low genital tract, $5(10.0 \%)$ and $3(12.0 \%)$ persons had ovarian cysts, $15(30.0 \%)$ and $7(28.0 \%)$ - disorders of menstrual cycle, $1(2.0 \%)$ and $1(4.0 \%)$ - infertility. The first premenstrual symptoms occurred in the analogous period in women with mild (22.88 \pm 0.99 years) and severe PMS (23.04 \pm 1.12 years).

There was no statistical difference in the levels of estradiol in blood serum in two phases of the menstrual cycle between controls and women with PMS (table 1). The concentration of estradiol increased in the luteal phase compared to the follicular one in all groups of women. But we found that the more growth of estradiol amount in the luteal phase compared to the follicular phase was in the patients with PMS than in healthy individuals. Thus, the rise of this hormone between two menstrual phases was on $45.83 \%$ in control group $(\mathrm{p}=0.002)$ and on $56.52 \%$ $(\mathrm{p}=0.01)$ in the basic group $(59.09 \%$ - I subgroup $(\mathrm{p}<0.001), 58.33 \%$ - II subgroup $(\mathrm{p}<0.001))$.

The distribution of the AG polymorphism of ESR1 gene demonstrated that the majority of the persons in the basic $(40.00 \%)$ and control $(60.00 \%)$ groups were the carriers of AG genotype (table 2). GG genotype was found in 4.4 times more often in the patients with PMS than in controls $\left(\chi^{2}=1.83, p=0.18, O R=5.36,95 \% \mathrm{CI}=0.64-44.62, \mathrm{p}=0.17\right)$. But in the II subgroup the individuals with AA genotype $(44.00 \%)$ slightly predominated above persons with other genotypes (GG and $\mathrm{AG}$ ) in this group. However, in the II subgroup the number of women with GG genotype was the largest compared to other groups and the frequency of patients with GG genotype was in 6.4 times more often than in control group $\left(\chi^{2}=3.52, \mathrm{p}=0.06, \mathrm{OR}=8.94,95 \%\right.$ $\mathrm{CI}=1.01-79.05, \mathrm{p}=0.049)$.

The study of the concentration of estradiol in relationship with genotype demonstrated that the levels of this hormone in the women with GG genotype in the basic group in two phases of the menstrual cycle were higher than in women with GG genotype in the control group but the data are not statistically significant because only one control person had GG genotype (table 3). A particularly pronounced tendency for the increased estradiol levels in women with the GG genotype was observed in the individuals with the severe form of PMS compared to controls. The persons in the II subgroup in the follicular phase had the increased estradiol level on $35.00 \%(p=0.09)$ higher, in the luteal phase - on $50.00 \%(p=0.04)$ than the individuals with AA genotype in this subgroup.

In healthy women the estradiol level in the luteal phase of the menstrual cycle was similar in the carriers of $G$ allele (GG + AG genotypes) compared to the carriers of only A allele (AA genotype) (table 4). In contrast, in the patients with PMS who are carriers of GG and AG genotypes there was a tendency in the luteal phase for an increased concen- 
Table I. The level of estradiol in two phases of the menstrual cycle in women with premenstrual syndrome and controls, nmol/I

\begin{tabular}{ccc}
\hline Group & Follicular phase & Luteal phase \\
\hline Control group, $\mathrm{n}=20$ & $0.24 \pm 0.02$ & $0.35 \pm 0.04^{*}$ \\
\hline Basic group (total PMS), $\mathrm{n}=50$ & $0.23 \pm 0.01$ & $0.36 \pm 0.02^{*}$ \\
\hline I subgroup (mild PMS), $\mathrm{n}=25$ & $0.22 \pm 0.02$ & $0.35 \pm 0.03^{*}$ \\
\hline II subgroup (severe PMS), $\mathrm{n}=25$ & $0.24 \pm 0.02$ & $0.38 \pm 0.03^{*}$ \\
\hline
\end{tabular}

Note: * - significance of difference of indicators between follicular and luteal phases $(p<0.05)$

Table II. Distribution of genotypes of AG polymorphism ESR1 gene in women with premenstrual syndrome and controls

\begin{tabular}{|c|c|c|c|c|c|c|}
\hline \multirow{2}{*}{ Group } & \multicolumn{2}{|c|}{ GG genotype } & \multicolumn{2}{|c|}{ AG genotype } & \multicolumn{2}{|c|}{ AA genotype } \\
\hline & Abs & $\%$ & Abs & $\%$ & Abs & $\%$ \\
\hline Control group, $n=20$ & 1 & 5.00 & 12 & 60.00 & 7 & 35.00 \\
\hline Basic group (total PMS), $n=50$ & 11 & 22.00 & 20 & 40.00 & 19 & 38.00 \\
\hline I subgroup (mild PMS), $\mathrm{n}=25$ & 2 & 12.00 & 14 & 56.00 & 8 & 32.00 \\
\hline II subgroup (severe PMS), n=25 & 8 & 32.00 & 6 & 24.00 & 11 & 44.00 \\
\hline
\end{tabular}

Table III. The level of estradiol in two phases of the menstrual cycle depending on AG polymorphism ESR1 gene in women with premenstrual syndrome and controls, nmol/l

\begin{tabular}{ccccc}
\hline Group & Menstrual phase & GG genotype & AG genotype & AA genotype \\
\hline Control group, $\mathrm{n}=20$ & Follicular & 0.11 & $0.25 \pm 0.03$ & $0.24 \pm 0.03$ \\
& Luteal & 0.21 & $0.38 \pm 0.06$ & $0.34 \pm 0.07$ \\
\hline \multirow{2}{*}{ Basic group (total PMS), $\mathrm{n}=50$} & Follicular & $0.24 \pm 0.03$ & $0.23 \pm 0.01$ & $0.22 \pm 0.02$ \\
& Luteal & $0.39 \pm 0.05$ & $0.40 \pm 0.04$ & $0.31 \pm 0.03$ \\
\hline \multirow{2}{*}{ I subgroup (mild PMS), $\mathrm{n}=25$} & Follicular & $0.17 \pm 0.01$ & $0.22 \pm 0.01$ & $0.24 \pm 0.04$ \\
& Luteal & $0.25 \pm 0.02$ & $0.38 \pm 0.05$ & $0.33 \pm 0.06$ \\
\hline \multirow{2}{*}{ II subgroup (severe PMS), $\mathrm{n}=25$} & Follicular & $0.27 \pm 0.03$ & $0.27 \pm 0.03$ & $0.20 \pm 0.01$ \\
& Luteal & $0.45 \pm 0.06$ & $0.45 \pm 0.08$ & $0.30 \pm 0.03$ \\
\hline
\end{tabular}

Table IV. Estradiol level in blood serum in the luteal phase of the menstrual cycle depending on AG polymorphism ESR1 gene in women with premenstrual syndrome and controls

\begin{tabular}{ccc} 
Group & GG+AG genotype & AA genotype \\
\hline Control group, $\mathrm{n}=20$ & $0.36 \pm 0.06$ & $0.34 \pm 0.07$ \\
\hline Basic group (total PMS), $\mathrm{n}=50$ & $0.40 \pm 0.03$ & $0.31 \pm 0.03$ \\
\hline I subgroup (mild PMS), $\mathrm{n}=25$ & $0.36 \pm 0.04$ & $0.33 \pm 0.06$ \\
\hline I subgroup (severe PMS), $\mathrm{n}=25$ & $0.45 \pm 0.05$ & $0.30 \pm 0.03$ \\
\hline
\end{tabular}

tration of estradiol in the blood on $29.03 \%$ compared with individuals with AA genotype. A significant difference in hormone concentration between the carriers of the G allele and carriers of only A allele was found in the persons with the severe form of PMS - by $50.00 \%(\mathrm{p}=0.02)$.

\section{DISCUSSION}

It is known that the psychological manifestations are typical for patients with PMS. They include increased anger level [20], neuroticism [21], depression [22] and other affective disorders [23]. Commonly such symptoms are connected with the hormonal processes. Estrogens and progesterone hormones are produced in the ovaries and brains, so, they affect as neurosteroids. That is why estradiol may contribute to the formation of affective dis- orders [22]. The greater role in the pathogenesis of PMS is usually associated with metabolites of progesterone (allopregnanolone) and its influence on gamma-aminobutyric acid receptors, so it has the meaning in the mood and affective processes [24]. Ordinarily, there is no statistical significance in the level of estradiol and progesterone in blood serum during the menstrual cycle between patients with PMS and healthy women [24]. Today there is the opinion that the hypersensitivity of the organisms to the female steroid hormones may explain the reaction of organisms to their changes during the menstrual cycle on the background of normal hormonal concentration [25]. Itsekson AM et al. found the positive correlation between skin sensitivity to progesterone and estrogens and PMS and the authors proposed desensitization procedure to relive the severity of clinical manifestation of the syn- 
drome [26]. Besides this, the cytokine factors can lead to different mood problems [27]. Thus, it was found that IL- $1 \beta$, IL-6, IL- 8 and IL-10 have correlative connections with mood states and stress hormones in female soccer players with PMS $[28,29]$.

In this study we found no difference in estradiol concentrations in two phases of the menstrual cycle between control persons and women with PMS that corresponds with the results of other scientists $[24,30]$. But the increase of this hormone in the luteal phase was more significant in patients with PMS especially with severe form compared to healthy individuals. The more rate of GG carriers was determined in the group of severe PMS persons (32.0 $\%$ versus $5.0 \%$ of controls). Besides this our results also confirm that the persons with G allele (GG+AG genotype) of have the increase of estradiol level in the luteal phase of the menstrual cycle compared to the individuals only with A allele (AA genotype). Also in women with severe PMS this difference was statistically significant. Withal, there was no difference in estradiol amount in the luteal phase of the menstrual cycle between the healthy women with $\mathrm{G}$ allele and the healthy individuals with only A allele. Yen JY et al. studied the estrogen level, emotional symptoms in the women with the most severe form of PMS - premenstrual dysphoric disorder [27]. The scientists determined the association between estrogen and increase anxiety. It is worth to mention that such association and dysfunctional emotional regulation existed only among the $\mathrm{G}$ carriers of ESR $\alpha$-Xbal polymorphism.

\section{CONCLUSIONS}

In patients with premenstrual syndrome, especially in persons with the severe form, the estradiol level is increased significantly more in the luteal phase compared to the follicular one than in healthy women. The rate of individuals with GG genotype is higher in women with severe premenstrual syndrome. The estradiol level in the luteal phase of the menstrual cycle is increased in the persons with severe premenstrual syndrome who are the carriers of $\mathrm{G}$ allele compared to the carriers of A allele. Thus, AG polymorphism of ESR1 gene may be the marker of development of premenstrual syndrome.

\section{REFERENCES}

1. Zendehdel M., Elyasi F. Biopsychosocial etiology of premenstrual syndrome: A narrative review. J Family Med Prim Care. 2018; 7 (2): 346-356.

2. Sattar K. Epidemiology of Premenstrual Syndrome (PMS)-A Systematic Review and Meta-Analysis Study.J J Clin Diagn Res. 2014;8 (2): 106-109.

3. Kues J.N., Janda C., Kleinstäuber M. Weise C. How to measure the impact of premenstrual symptoms? Development and validation of the German PMS-Impact Questionnaire. Women Health. 2016; 56 (7): 807-826.

4. Ryu A., Kim T.H. Premenstrual syndrome: A mini review. Maturitas. 2015; 82 (4): 436-440.

5. Ranjbaran M., Omani Samani R., Almasi-Hashiani A., Matourypour P. et al. Prevalence of premenstrual syndrome in Iran: A systematic review and meta-analysis. Int J Reprod Biomed (Yazd). 2017; 15(11): 679-686.
6. Yang J., Joe S.H., Lee M.S., Kim S.H. Survey of premenstrual symptom severity and impairment in Korean adolescents: premenstrual dysphoric disorder, subthreshold premenstrual dysphoric disorder and premenstrual syndrome. Asia Pac Psychiatry. 2014; 6 (2): 135-144.

7. Akarsu R.H., Alsac S.Y. Risks with Gynaecological problems on the health of University Students. Pak J Med Sci. 2019; 35 (3): 758-763.

8. Abeje A., BerhanuZ. Premenstrual syndrome and factors associated with it among secondary and preparatory school students in Debremarkos town, North-west Ethiopia, 2016. BMC Res Notes. 2019; 12 (1): 535.

9. Biggs W.S., Demuth R.H. Premenstrual syndrome and premenstrual dysphoric disorder. Am Fam Physician. 2011; 84 (8): 918-924.

10. American College of Obstetricians and Gynecologists. Guidelines for Women's Health Care: A Resource Manual. 4th ed. Washington, DC: American College of Obstetricians and Gynecologists. 2014: 607- 613

11. Green L.J., O'Brien P.M.S., Panay N., Craig M. On behalf of the Royal College of Obstetricians and Gynaecologists. Management of premenstrual syndrome. BJOG. 2017; 124: e73-e105.

12. Ismaili E., Walsh S., O'Brien P.M.S. et al. Fourth consensus of the International Society for Premenstrual Disorders (ISPMD): auditable standards for diagnosis and management of premenstrual disorder. Arch Womens Ment Health. 2016; 19 (6): 953-958.

13. Victor F.F., Souza A.I., Barreiros C.D.T., Barros J.L.N. et al. Quality of Life among University Students with Premenstrual Syndrome. Rev Bras Ginecol Obstet. 2019; 41 (5): 312-317.

14. Arab A., Golpour-Hamedani S., Rafie N. The Association Between Vitamin D and Premenstrual Syndrome: A Systematic Review and Meta-Analysis of Current Literature. J Am Coll Nutr. 2019: 1-9.

15. Abdi F., Ozgoli G., Rahnemaie F.S. A systematic review of the role of vitamin $D$ and calcium in premenstrual syndrome. Obstet Gynecol Sci. 2019; 62 (2): 73-86.

16. Abdollahifard S., Rahmanian Koshkaki A., Moazamiyanfar R. The effects of vitamin $B 1$ on ameliorating the premenstrual syndrome symptoms. Glob J Health Sci. 2014; 6 (6): 144-153.

17. Jafari F., Amani R., Tarrahi M.J. Effect of Zinc Supplementation on Physical and Psychological Symptoms, Biomarkers of Inflammation, Oxidative Stress, and Brain-Derived Neurotrophic Factor in Young Women with Premenstrual Syndrome: a Randomized, Double-Blind, Placebo-Controlled Trial. Biol Trace Elem Res. 2019. doi: 10.1007/s12011-019-01757-9.

18. Kamat S.V., Nimbalkar A., Phatak A.G., Nimbalkar S.M. Premenstrual syndrome in Anand District, Gujarat: A cross-sectional survey. J Family Med Prim Care. 2019; 8(2): 640-647.

19. Prozatverdzhenniaklinichnykh protokolivzakusherskoitahinekolohichnoi dopomohy: nakaz M-va okhorony zdorovia Ukrainy № 676 vid 31.12.2004 r. 2014. [Approval of clinical protocols for obstetric and gynecological care]. https://z-I.com.ua/ru/new319/\#pms. (In Ukrainian).

20. Saglam H.Y., Basar F. The relationship between premenstrual syndrome and anger. Pak J Med Sci. 2019; 35 (2): 515-520.

21. Del Mar Fernández M., Regueira-MéndezC., Takkouche B. Psychological factors and premenstrual syndrome: A Spanish case-control study. PLoS One. 2019; 14 (3): e0212557.

22. Rubinow D.R., Schmidt P.J. Sex differences and the neurobiology of affective disorders. Neuropsychopharmacology. 2019; 44 (1): 111-128.

23. Rubinow D.R., Schmidt P.J. Is there a role for reproductive steroids in the etiology and treatment of affective disorders? Dialogues Clin Neurosci. 2018; 20 (3): 187-196.

24. Schiller C.E., Schmidt P.J., Rubinow D.R. Allopregnanolone as a mediator of affective switching in reproductive mood disorders. Psychopharmacology (Berl). 2014; 231 (17): 3557-3567. 
25. Ryu A., Kim T.H. Premenstrual syndrome: A mini review. Maturitas. 2015; 82 (4): 436-440.

26. Itsekson A.M., Yonit B., Ze'ev I.H., Matitiyahu Z., et al. Safety and value of skin test to sex hormones and sex hormone sensitivity desensitization in women with premenstrual syndrome. World Allergy Organ J. 2019; $12(6): 100041$.

27. Yen J.Y., Wang P.W., Su C.H., Liu T.L. et al. Estrogen levels, emotion regulation, and emotional symptoms of women with premenstrual dysphoric disorder: The moderating effect of estrogen receptor $1 a$ polymorphism. Prog Neuropsychopharmacol Biol Psychiatry. 2018; 82: 216-223.

28. Foster R., Vaisberg M., Bachi A.L.L. et al. Premenstrual Syndrome, Inflammatory Status, and Mood States in Soccer Players. Neuroimmunomodulation. 2019; 26 (1): 1-6.

29. Foster R., Vaisberg M., Araújo M.P. et al. Relationship between Anxiety and Interleukin 10 in Female Soccer Players with and Without Premenstrual Syndrome (PMS). Rev Bras Ginecol Obstet. 2017; 39 (11): 602-607.

30. SchillerC.E., Johnson S.L., Abate A.C. et al. Reproductive Steroid Regulation of Mood and Behavior. Compr Physiol. 2016; 6 (3): 1135-1160.

The authors would like to thank colleges of Department of Medical Genetics, Shupyk National Medical Academy of Postgraduate Education (Kyiv, Ukraine) for help in the research of gene polymorphism.

\section{ORCID and contributionship:}

Lyudmyla V. Pakharenko: 0000-0003-4774-8326 A, B, D, E, F

Yuri P. Vdovichenko: 0000-0001-5869-4437 A, E, F

Nataliia Ya. Kurtash: 0000-0003-4538-8734 ${ }^{\text {B, C }}$

Iryna O. Basiuha: 0000-0002-4205-386X ${ }^{B, C}$

Inna V. Kravchuk: 0000-0003-4550-0415 B, C

Volodymyr D. Vorobii: 0000-0003-2530-5276 ${ }^{\text {D, E }}$

Olena M. Kusa: 0000-0002-8881-3756 ${ }^{\text {B, C }}$

\section{Conflict of interest:}

The Authors declare no conflict of interest.

\section{CORRESPONDING AUTHOR}

\section{Lyudmyla V. Pakharenko}

Ivano-Frankivsk National Medical University

106/14 Konovaltsya Str., 76014 Ivano-Frankivsk, Ukraine

tel: +380974306921

e-mail:ludapak@ukr.net

Received: 21.11.2019

Accepted: 03.09.2020

A - Work concept and design, B - Data collection and analysis, C - Responsibility for statistical analysis,

D - Writing the article, $\mathbf{E}$-Critical review, $\mathbf{F}$ - Final approval of the article 